Research Article

\title{
Effect of Microwave or Ultrasound Irradiation in the Extraction from Feather Keratin
}

\author{
Isis S. Rodríguez-Clavel ${ }^{(D,},{ }^{1,2,3}$ Silvia P. Paredes-Carrera, ${ }^{1}$ Sergio O. Flores-Valle, ${ }^{2}$ \\ Eri J. Paz-García $\mathbb{D}^{1,},{ }^{1,2}$ Jesús C. Sánchez-Ochoa, ${ }^{1}$ and Rosa M. Pérez-Gutiérrez $\mathbb{D D}^{3}$ \\ ${ }^{1}$ Laboratorio de Nanomateriales Sustentables, Escuela Superior de Ingeniería Química e Industrias Extractivas \\ (ESIQIE)-Instituto Politécnico Nacional, Edif Z-5 2do piso UPALM Zacatenco, c.p. 07738, CDMX, Mexico City, Mexico \\ ${ }^{2}$ Laboratorio de Química Verde, Escuela Superior de Ingeniería Química e Industrias Extractivas \\ (ESIQIE)-Instituto Politécnico Nacional, Edif Z-6 3er piso UPALM Zacatenco, c.p. 07738, CDMX, Mexico City, Mexico \\ ${ }^{3}$ Laboratorio de Investigación de Productos Naturales, Escuela Superior de Ingeniería Química e Industrias Extractivas \\ (ESIQIE)-Instituto Politécnico Nacional, Edif Z-6 3er piso UPALM Zacatenco, c.p. 07738, CDMX, Mexico City, Mexico
}

Correspondence should be addressed to Isis S. Rodríguez-Clavel; isis.sch.rdz.clavel@hotmail.com

Received 25 July 2019; Revised 24 October 2019; Accepted 30 October 2019; Published 6 December 2019

Academic Editor: Dario Pasini

Copyright ( 2019 Isis S. Rodríguez-Clavel et al. This is an open access article distributed under the Creative Commons Attribution License, which permits unrestricted use, distribution, and reproduction in any medium, provided the original work is properly cited.

\begin{abstract}
The extraction of feather keratin biopolymer structures was studied using chicken feathers as a biomass material by the cold acid hydrolysis reaction; the recrystallization stage was performed using microwave or ultrasound irradiation, and conduction heating was used as a reference. The microwave or ultrasound irradiation modified the texture and the morphology of the obtained materials, and they can be controlled depending on the time exposure and the power of the irradiation; this has high relevance in the design of new materials to obtain nanostructures depending on the specific application. It was found that the microwave irradiation promotes the growth of the beta sheet over the alpha helix, and in the case of ultrasound irradiation, the growth is reversed being similar to the conduction heating; the porosity properties remain invariant, modifying the particle sizes depending on the exposure time and power of irradiation. Therefore, the feather keratin biopolymer, when modified by microwaves and ultrasound in the recrystallization stage, is a fibrous protein that has good mechanical, structural, morphological, and thermal properties with potential applications such as development of biocompatible materials with cellular interaction and in catalysis as catalytic and enzymatic support to mention just a few.
\end{abstract}

\section{Introduction}

Keratin is an essential part of wool, hair, nails (hooves), feathers, and horns of different animals, providing mechanical and protective support in adapting to the ecosystem [1]. It is one of the most abundant and unexplored structural protein sources contained in epithelial cells and together with collagen are the most important biopolymers found in biological structures [2]. Keratin is a fibrous protein composed of more than 20 amino acids, among which stand out by composition are cystine (8-11\%), glycine (8-13\%), proline (6-9\%), and serine (9-14\%), with lower contents of lysine, histidine, methionine, and tryptophan [3].
Cystine determines the structure of keratin depending on the content of the former, that is, to say in the form of alpha helix (Figure 1(a)) or beta sheet (Figure 1(b)), and this has an essential role in the determination of the physicochemical properties of keratin. Cystine promotes electrostatic attraction with other species and the formation of covalent bonds with amino groups, providing structures with rigidity and thermostability; also, it promotes the union between amino acids of the main chain of proteins [5].

The interactions that maintain the stability of the structure of the proteins (Figure 1) are the disulfide bridges (S-S bond between two cysteines), hydrogen bond (the $\mathrm{H}^{+}$ interacts with an $\mathrm{O}^{-}$), ionic interaction (between carboxylic 


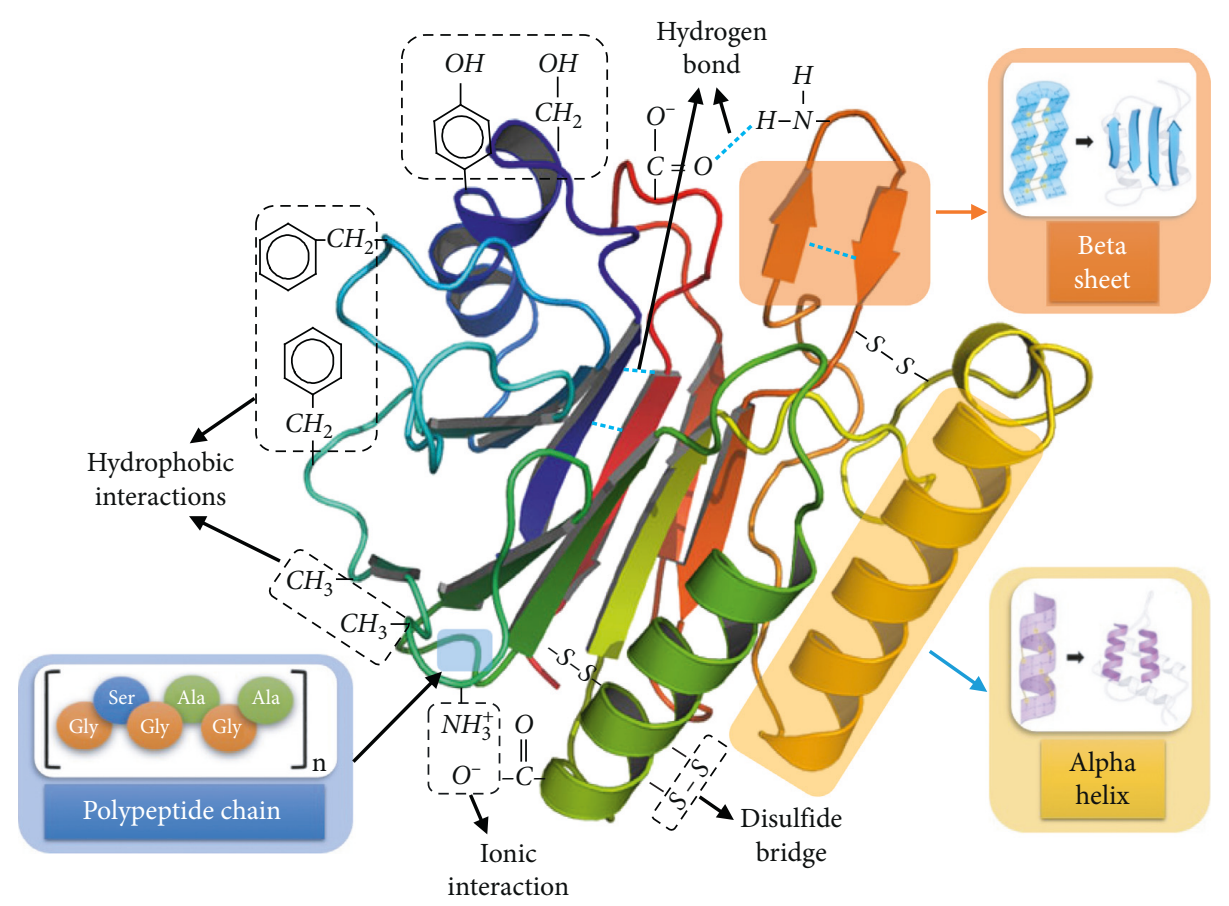

FIGURE 1: The different interactions that maintain the stability of the protein structures (edited by the author [4]).

anions and ammonium cations), and hydrophobic interactions (apolar interactions) [6,7]. These interactions are dependent on the $\mathrm{pH}$ of the medium in which the protein is found, thereby modifying the charges of the functional groups which are present; the ammonium and carboxyl groups can be modified with a change of the $\mathrm{pH}$, having a neutral charge in a zwitterion form at the isoelectric point $(\mathrm{pH}=4.9)$. These interactions are reduced by protonation of the carboxylic group at a $\mathrm{pH}$ lower than 4.9 and deprotonation of the amine group at a $\mathrm{pH}$ greater than $4.9[8,9]$.

Keratin has been combined with other materials to obtain composites and hybrid materials, depending on the type of interaction between the materials. These products have been studied and used in various areas: cosmetics, in the development of personal care products, medicine, in the development of biocompatible materials with good cellular interaction, environmental, as an adsorbent of contaminants, and catalysis, as catalytic support for species such as hydrotalcites-enzymes-zeolites-metals $[5,10,12]$. Due to its applications, it is considered a value-added product that has been studied in recent years, hence the importance of being able to extract it from waste products such as bird feathers and human hair. The chicken feather fiber is composed by hydrophobic keratin, a protein that has resistance similar to that of nylon, but with a smaller diameter than that of wood fiber [13], and it has the potential to be an efficient and lowcost raw material for the synthesis of natural fibrous biopolymers.

The main methods that have been used for the extraction of keratin from biostructures are the reduction with urea [14], oxidation with acids [15], microwave irradiation [16], extraction with alkalines [17], sulfitolysis [18], and ionic liquids [19].
According to the literature which uses high temperature conditions $\left(T>120^{\circ} \mathrm{C}\right)$, long extraction times $(72 \mathrm{~h})$, nonecological reagents (concentrated acids and bases), and yields below $80 \%$ of keratin extraction, in this study we proposed the oxidation method with a 50\% diluted acid, assisted with microwave and ultrasound irradiation, which has not been reported yet in the recrystallization stage. These irradiation methods have advantages over conventional treatments (conduction and convection heating), such as faster heating rate and greater efficiency in crystallization kinetics, and in addition, they allow the formation of nanostructures with different morphologies and textures depending on the type, time, and power of the irradiation $[20,22]$.

The objective of this work was the evaluation of the morphology and texture in the recrystallization stage of keratin, as well as to study the changes in the secondary structure (alpha or beta) and tertiary structure (peptide bonds) at different times and irradiation power.

\section{Materials and Methods}

2.1. Materials. The raw material of the present work was chicken feathers, which were obtained from the east of Mexico City. The reagents used for the extraction and purification of the keratin were distilled water, sulfuric acid (Fermont, 98.08\%), sodium hydroxide (J.T. Baker, 98.4\%), and ethanol (CIM).

\subsection{Feather Keratin Obtention}

2.2.1. Pretreatment of Chicken Feathers. The feathers were washed with sodium hypochlorite solution at room temperature $\left(25^{\circ} \mathrm{C}\right)$ in order to eliminate blood, fecal matter, and 
pathogens present in them. Subsequently, the feathers were dried at a temperature of $40^{\circ} \mathrm{C}$ for $6 \mathrm{~h}$. The dry feathers were cut to an approximate size of $5 \mathrm{~mm}$. It is emphasized that all parts of the feathers were used.

After the cutting of the feathers, the Soxhlet technique was used to eliminate the superficial fat that protects the feathers, to obtain keratin free of impurities, and to calculate the total yield in the obtained feather keratin.

2.2.2. Soxhlet Method. The method consisted of a semicontinuous lipid extraction [23] using ethyl ether as a dissolvent; the system was heated up to produce 10 cycles of filling and siphoning in the extractor tube (3 hours approximately). The dry material was stored in hermetic bags for later use.

2.2.3. Feather Keratin Extraction (K). The process was a modification of the Rangel method [24], employed in the recrystallization stage microwave or ultrasound irradiation at different times $(5,10$, and 15 minutes).

The feathers were placed in a beaker with a sulfuric acid solution $1: 1\left(\mathrm{H}_{2} \mathrm{O}-\mathrm{H}_{2} \mathrm{SO}_{4}\right)$. The mixture was stirred for $12 \mathrm{~h}$ at a temperature of $50^{\circ} \mathrm{C}$, and the $\mathrm{pH}$ was adjusted between 4 and 5 (isoelectric point of keratin) with a $5 \mathrm{M}$ sodium hydroxide solution. The mixture was left at rest for $24 \mathrm{~h}$, and then the solid phase was separated by decantation. Two options were employed to wash the crystals: (a) in ethanolwater $(1: 1)$ and (b) in water. In both cases, the solids were dissolved in $140 \mathrm{ml}$ of water or ethanol-water, and the solid impurities were eliminated from the solution by filtration.

(a) The sample treated with ethanol-water was divided into 7 samples of $20 \mathrm{ml}$ each. The samples $1-3$ were subjected to 5,10 , and 15 minutes of irradiation with microwaves (brand LG at $960 \mathrm{~W}$ and $2450 \mathrm{~Hz}$ ), and the samples were named as follows: KEt5M, KEt10M, and KEt15M, respectively; the samples 4-6 were irradiated with ultrasound (ultrasonic bath brand Elma D-78224 at $3.8 \mathrm{~kW}$ and $45 \mathrm{kHz}$ ) for 5, 10, and 15 minutes, and in this case, the samples were named KEt5U, KEt10U, and KEt15U, respectively; the last one did not receive any treatment (sample named KEt). All the samples were heated at $70^{\circ} \mathrm{C}$ until obtaining the recrystallized phase.

(b) In the case of the dilution treated with water, the process was repeated with one single sample named $\mathrm{KC}$, which did not receive any treatment of microwave or ultrasound irradiation.

Methodology of feather keratin obtention is shown in Figure 2.

2.3. Characterization. The materials obtained were characterized by Fourier transform infrared spectroscopy, and the significant absorption bands of the characteristic functional groups of the precursors and products were identified. The infrared spectra were obtained on a Perkin Elmer Spectrum 100 spectrometer in a range of $400-3000 \mathrm{~cm}^{-1}$. The X-ray diffraction patterns were collected with a Rigaku Miniflex 600 diffractometer using $\mathrm{Cu} \mathrm{K} \alpha$ radiation $(\alpha=1.54 \AA)$. A Soller slit with a Ni filter of $0.5 \mathrm{~mm}$ was fitted in the incident beam, and an ultra high-speed Dtex detector was used. Measurements were performed with a sweep from 15 to 40 degrees with a step size of 0.01 and a speed of 5 degrees $/ \mathrm{min}$.

The textural properties of the synthesized materials were characterized by nitrogen physisorption in a Gemini VII Surface Area Analyzer. The specific surface area was determined by the BET (Brunauer, Emmett, and Teller) multipoint method with a pretreatment at a temperature of $150^{\circ} \mathrm{C}$ for $8 \mathrm{~h}$ under vacuum. The pore size was determined by the BJH (Barrett, Joyner, and Halenda) method.

The SEM micrographs were obtained in a JEOL scanning electron microscope model JSM7800F at $2 \mathrm{kV}$ and a low electron detector (LED). The samples were placed on a conductive carbon tape, and they were covered by a gold film to be analyzed.

The Particle size was analyzed on a Zetasizer nano ZSP device. The system incorporates an analyzer of particle size or two-angled molecule size for the improved detection of aggregates and the measurement of small or diluted samples at a concentration in $\mathrm{ppb}$ or $\mathrm{ppm}$, using dynamic light scattering with NIBS optics (noninvasive backscatter).

\section{Results and Discussion}

3.1. Percentage Determination of Grease Content in Chicken Feathers. The percentage of grease content in the feathers $G$ (\%) was determined three times, according to the following equation:

$$
G(\%)=\frac{m_{2}-m_{1}}{M} \times 100,
$$

where $m_{1}$ is the mass of the empty flask, $m_{2}$ is the mass of grease without organic dissolvent in the flask, and $M$ is the initial sample; all the measurements were in grams. Table 1 shows the percentage of grease obtained.

It is observed that on average the grease percentage of the feathers is $1.5 \%$, which is within the one found in other works (5\%) [7].

3.2. Fourier Transform Infrared Spectroscopy FTIR. The infrared spectra for the KEt and KC samples (Figure 3) show the characteristic signals of keratin, mainly the peptide bonds present in the structure such as amide A and amide I, II, and III. The amide A band at $v=3300 \mathrm{~cm}^{-1}$ is connected to the stretching vibration of the $\mathrm{N}-\mathrm{H}$ bonds, and in the interval of $v=1700-1600 \mathrm{~cm}^{-1}$, the bands of the stretching vibrations of the $\mathrm{C}-\mathrm{O}$ bonds correspond to amide $\mathrm{I}$. At $v=1560 \mathrm{~cm}^{-1}$, a weak signal was found which is related to the flexion of the $\mathrm{N}-\mathrm{H}$ bond and is overlapped with the $\mathrm{C}-\mathrm{H}$ stretch bond corresponding to the amide II. In the interval $v=1250-1270 \mathrm{~cm}^{-1}$ appears a signal which corresponds to amide III that is the result from the stretching of the $\mathrm{C}-\mathrm{N}$ and $\mathrm{N}-\mathrm{H}$ bonds in the flat flexion, as well as the C-C bonds and the C-O stretching vibrations $[25,26]$.

The intense peaks at $1080 \mathrm{~cm}^{-1}$ and $1070 \mathrm{~cm}^{-1}$ are related to the asymmetrical and symmetric S-O and O-O stretching vibration bonds of the Bunte salt residues [23, 25, 27]. It can 


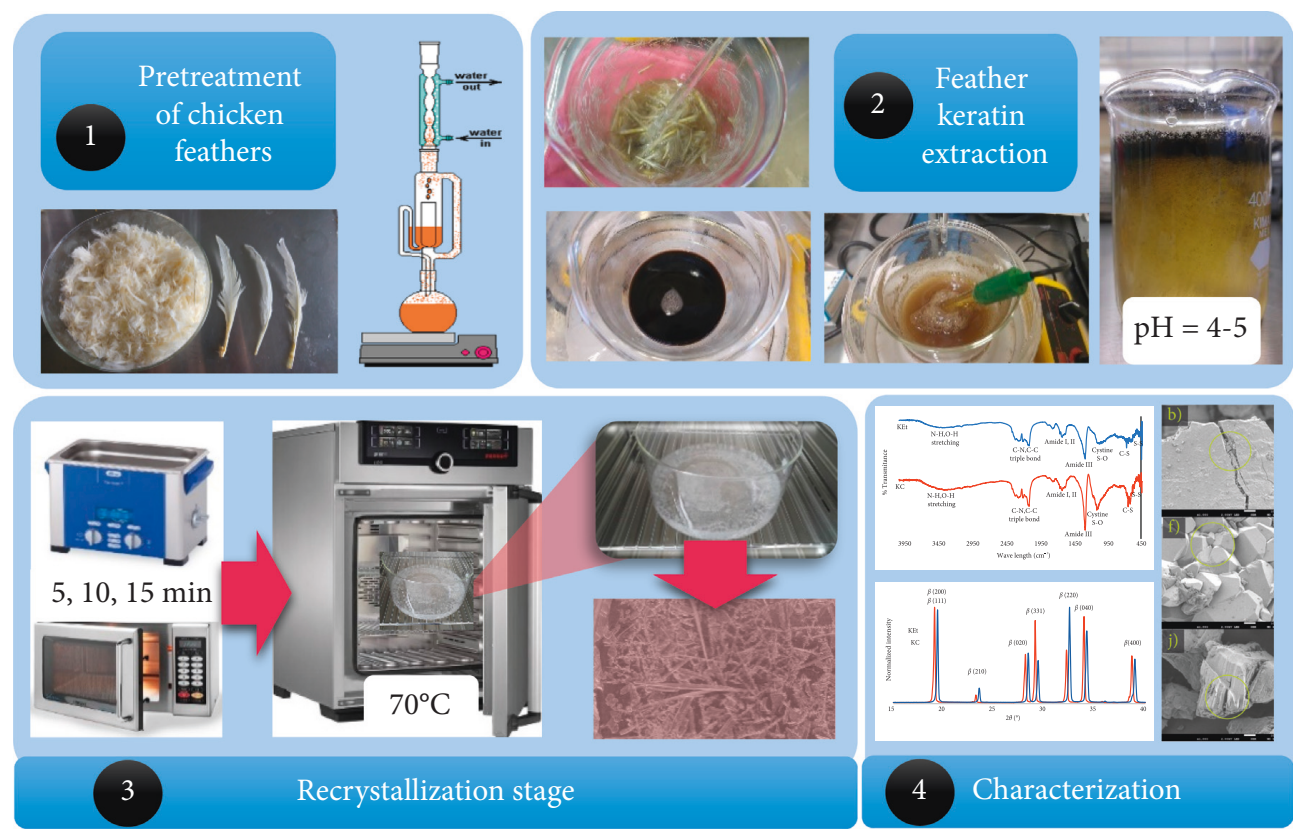

FIgURE 2: Stages of the experiment.

TABLE 1: Feather grease percentages.

\begin{tabular}{lcc}
\hline Sample & Mass $(\mathrm{g})$ & Grease $(\%)$ \\
\hline 1 & 1.009 & 1.6 \\
2 & 1.037 & 1.3 \\
3 & 1.053 & 1.7 \\
\hline
\end{tabular}

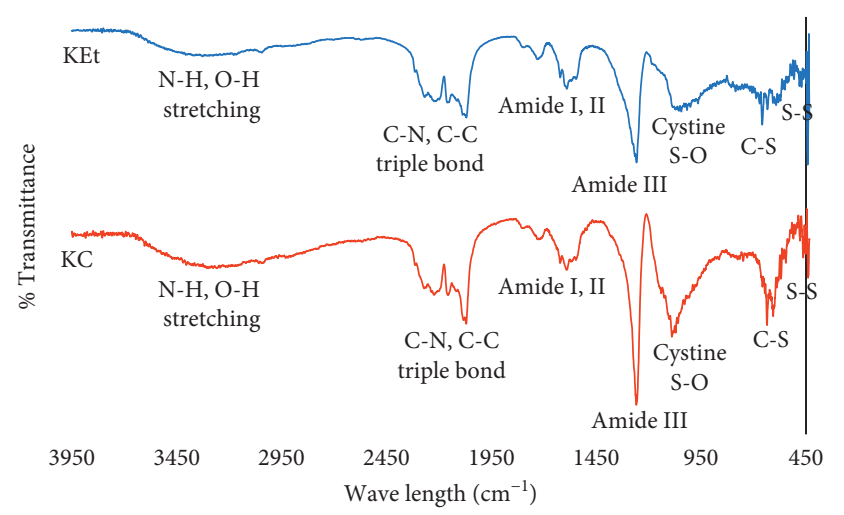

Figure 3: FTIR spectra of the KC and KEt samples.

be seen that the $\mathrm{KC}$ sample has more intense signals than the KEt sample.

3.3. X-Ray Diffraction. In a study conducted by Murrell [28], a diffractogram of sheep wool powder was reported in its natural state, which was used as the reference for the present work of the Miller indexes which identifies in the case of the alpha keratin structure: (040), (331), (321), (112), (120), (020), (001), and (010) and for the beta keratin structure: (400), (220), (020), (210), (200), and (001).

In Figure 4, the KC and KEt samples are compared with the crystallographic directions found in the Murrell study.

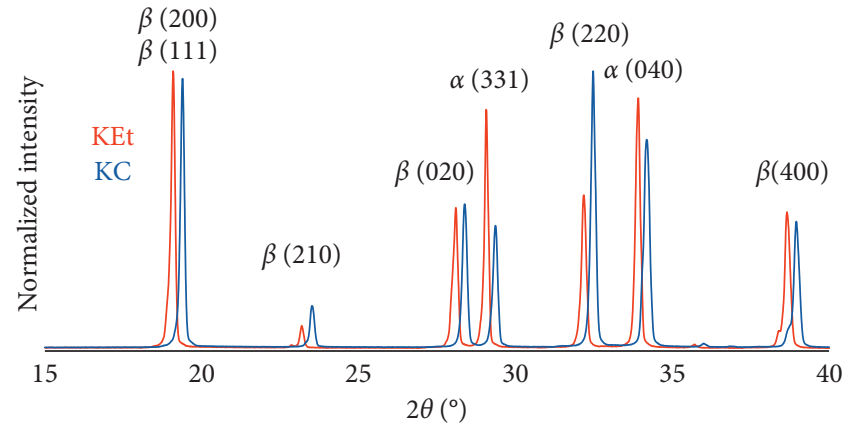

FIgURE 4: Diffractograms of the KC and KEt samples.

According to what was presented in the study carried out by Murrell, it was observed that the KC and KEt samples presented the crystallographic reflections for alpha keratin (331) and (040) and for beta keratin (111), (200), (020), (220), and (400), the latter with a greater amount of signals; therefore, the beta structure predominates in both materials. Both samples have good order and do not present crystalline impurities; this can be attributed to the cold hydrolysis treatment with sulfuric acid to which the material was subjected during the extraction.

Higher crystallinity was observed in the KEt sample because it was washed with an ethanol-water mixture unlike the KC sample which was washed only with water; the type of washing allowed a more efficient separation of the keratin with the residual organic matter, and this is because the dielectric constant $(\varepsilon r)$ of the alcohol $(\varepsilon r=24)$ is lower than the dielectric constant of the water $(\varepsilon r=80)$, which produces an increase in the attraction forces between opposite charges decreasing the degree of ionization of the protein radicals; as a consequence, there is a decrease in the solubility of keratin promoting a recrystallization in a more orderly manner. In 
addition, a signal shift to the left of approximately $0.5^{\circ}$ is observed, which indicates a small increase in the interplanar spacing. Therefore, the most efficient experimental procedure for the extraction and recrystallization was with a mixture of ethanol-water (KEt). Subsequent samples were washed with this solution.

Figures 5 and 6 show the X-ray diffraction patterns for the microwave (KEtM series) and ultrasound (KEtU series) treatments at different irradiation times $(5,10,15 \mathrm{~min})$ compared to the sample without treatment in the stage of recrystallization.

A decrease in crystallinity was observed when the irradiation time increased from 5 to 10 and 15 minutes based on the signal (111), and it is worth mentioning that the sample irradiated at 10 minutes has lower crystallinity than the ones at 5 and 15 minutes, so that the most crystalline sample was obtained at $5 \mathrm{~min}$ of irradiation, and this was the optimal treatment time used in this work; when comparing KEt5M sample with KEt sample, KEt5M is slightly more ordered.

According to the Miller indeces presented by Murrell and the intensity of the signals, the morphology that predominates in this treatment is a beta sheet, having a smaller number of alpha helixes which present crystallographic directions according to Murrell in $19^{\circ}(120)$ and (020), $21^{\circ}$ (112) and (321), and $28^{\circ}$ (331) and $34^{\circ}(040)$, and in our case, the alpha helix signals are only observed in the directions $28^{\circ}$ (331) and $34^{\circ}(040)$.

In Figure 6, it can be seen that the samples treated with ultrasound are less crystalline than the KEt sample; by increasing the irradiation times, the signals become wider which indicates a decrease in the crystal size, and by increasing the time from 5 to 10 , there are increments in the crystallinity in the direction (111) and between the directions (020) and (331); on the other hand, when irradiation time increases from 10 to 15 minutes there is a loss of crystallinity, and this effect has been observed in other works [29] which could be attributed to the cavitation phenomenon, ultrasound waves generate implosions which promote changes in crystallinity. The sample irradiated with 5 minutes of ultrasound presented the best crystalline characteristics when compared with the KEt sample; therefore, it is the optimal time for ultrasound irradiation as well as with the microwave method.

Figure 7 shows the comparison of X-ray diffraction patterns at 5 minutes of treatment with microwaves and ultrasound with the KEt sample.

It can be analyzed in Figure 6 that the beta sheet structure predominates in the 3 samples. This could be explained since the aforementioned structure is more stable to the difference in temperatures than alpha helix structure during the synthesis processes. It has been found that the alpha helix structure can be converted to beta sheet structure with an increase of heat and humidity; however, this modification is not stable [30]. In the case of the sample irradiated by the microwave in the crystallization stage due to the uniform heat generated by this technique, the structure of the material is oriented towards the beta sheet structure; in the obtained sample when using

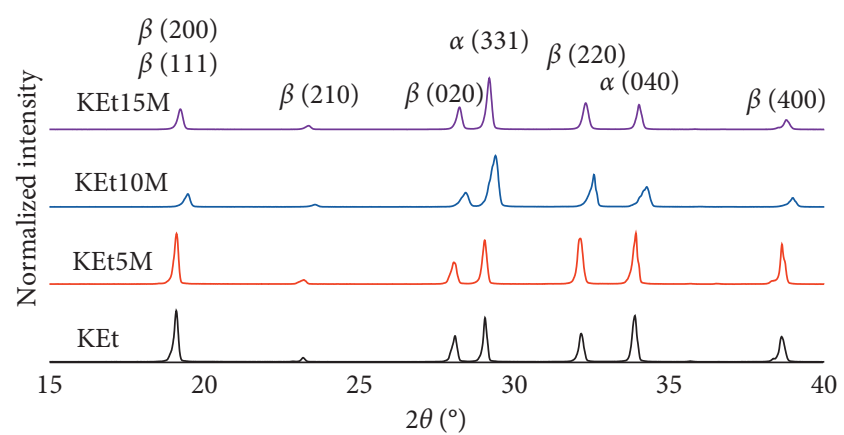

FIGURE 5: X-ray diffraction patterns for the KEtM series assisted in recrystallization with microwaves at 5,10 , and 15 min of irradiation compared with the KEt sample without treatment.

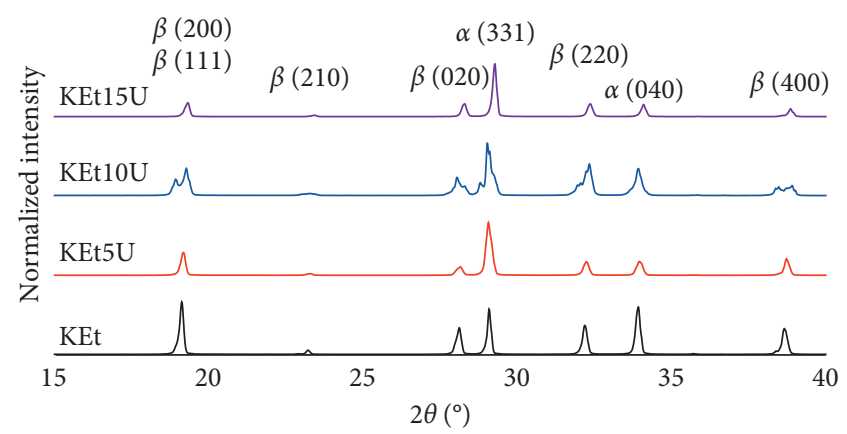

FIgURE 6: X-ray diffraction patterns for the KEtU series assisted in recrystallization with ultrasound at 5,10 , and 15 min of irradiation compared with the KEt sample without treatment.

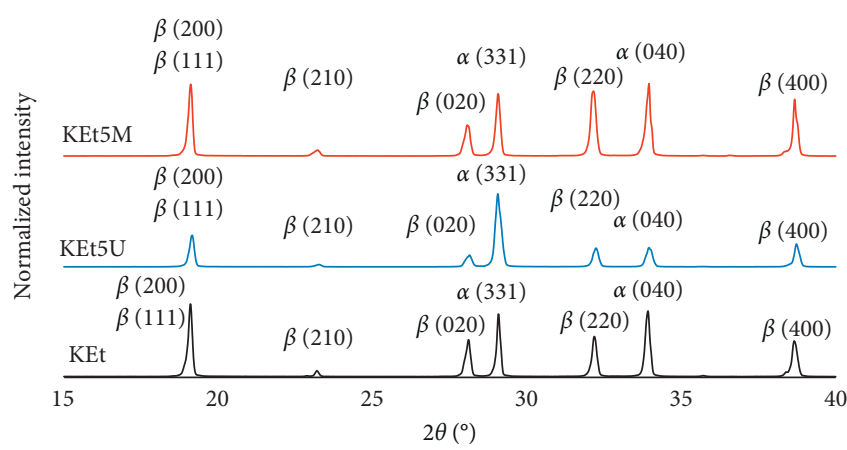

FIgURE 7: X-rays diffraction patterns for the KEt5M, KEt5U, and KEt samples.

ultrasound, the implosions are generated with high temperatures in a very short time, and it also favors the beta sheet structure. On the other hand, the alpha helix structure had a lower growth in the 040 direction when it was irradiated with ultrasound in comparison with the sample irradiated by microwaves and had an inverse effect in the (331) direction.

When comparing KEt5M sample with the conduction heating (KEt) sample, they do not present a significant change in their crystallinity. However, the KEt5U sample showed a lower crystallinity when compared with both. It can be observed based on the width of the signals that the crystal sizes are similar. 
3.4. Thermogravimetric Analysis (TGA). Thermogravimetric analysis shows that the obtained chicken feather keratin is a material resistant to high temperatures (thermostable) when it is subjected to a heat up to $800^{\circ} \mathrm{C}$, and no change in the weight of the sample was observed.

3.5. Nitrogen Physisorption (BET). The technique of nitrogen physisorption allowed the determination of the specific surface area, the pore diameter, and the pore volume, and by using the $\mathrm{BJH}$ method, the pore size distribution was obtained.

The KC sample has an isotherm of the type IV corresponding to nonporous solids. Samples KEt5M and KEt5U resulted in isotherms of the type II characteristic of mesoporous solids and with similar surface areas (Table 2). In all cases, atypical hysteresis cycles were presented due to nonporous materials. The increase in the specific surface area (which is a consequence of the synthesis method) could have beneficial effects in the interaction with other materials for being used in some applications.

Table 2 shows the comparison of the specific surface areas for the feather keratin samples extracted by the conduction heating, microwave, and ultrasound methods.

It was found that the use of microwaves and ultrasound during the recrystallization stage increases the specific surface area of the materials, generating mesoporous materials.

Figure 8 shows the distribution of the different pore sizes of the KC, KEt5U, and KEt5M samples.

It can be confirmed that all the prepared materials are mesoporous, with radii from 50 to $300 \AA$. So, the recrystallized material by the method of conduction heating is more homogeneous than the materials recrystallized by microwaves and ultrasound irradiation.

Figure 9 shows the images by optical microscopy obtained in the recrystallization stage for the (a) KC, (b) KEt5M, and (c) KEt5U samples.

It could be corroborated that the resulting morphology was different and dependent on the treatment method during the recrystallization stage of the feather keratin. In Figure 9(a), semicompact aggregates of structures predominantly in the form of very thin leaflets were observed for the KC sample. In Figure 9(b), in the case of the sample irradiated by microwaves (KEt5M), aggregates of smaller size than the ones by KC sample were observed and form needles whose growth is from the inside out with ramifications, and in Figure 9(c), in the case of the sample treated by ultrasound (KEt5U), a predominant morphology can be observed composed of aggregates of larger size needles with an undefined orientation and to a lesser extent, another phase formed by faceted particles.

3.6. Scanning Electron Microscopy (SEM). Figure 10 shows the scanning electron micrographs at different magnifications.

It is observed for the KC sample (Figures 10(a)-10(d)) that it is characterized by irregularly shaped faceted particles with no defined geometry (Figure 10(a)). For microgram (Figure 10(b)), there are compact solid particles with small surface agglomerates giving the material the characteristic of low porosity. At higher magnifications (Figures 10(b) and
TABLE 2: Specific surface area and pore diameter of KC, KEt5U, and KEt5M samples.

\begin{tabular}{lcc}
\hline Sample & Specific surface area $\left(\mathrm{m}^{2} / \mathrm{g}\right)$ & Pore diameter $(\AA)$ \\
\hline KC & 0.1 & 99.5 \\
KEt5U & 0.5 & 29.3 \\
KEt5M & 0.5 & 28.6 \\
\hline
\end{tabular}

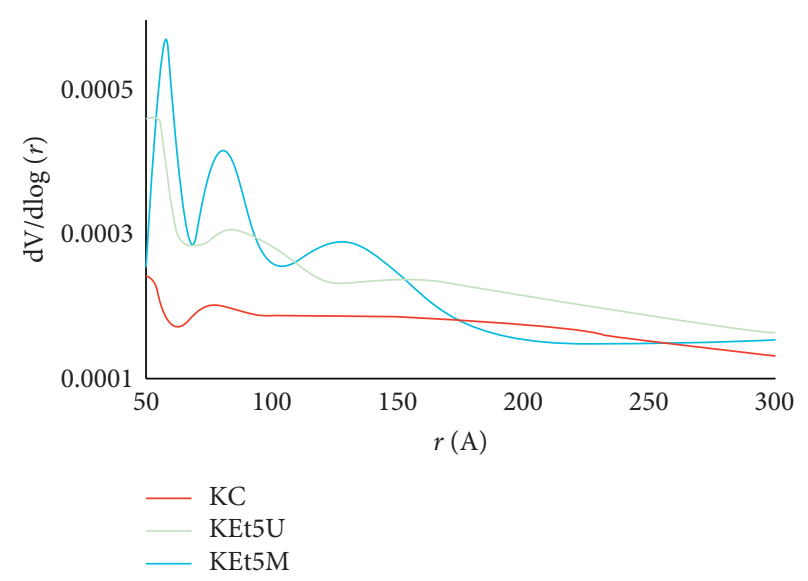

FIGURE 8: Pore distribution of the KC (a), KEt5US (b), and KEt5M (c) samples.

10(c)) are compact surfaces with fissures, showing agglomerated particles in different directions (marked areas); with a greater magnification (Figure 10(d)) there is a growth of these agglomerates which occur at different planes and orientations.

For the KEt5M sample, Figure 10(e) presents irregularly shaped faceted particles with a better size distribution than the sample KC; at higher magnifications (Figures 10(f) and 10(g)), we identified particles with flat faces and defined edges (prismatic geometry), which could indicate a material with a better crystallographic ordering, which coincides with the XRD diffraction patterns previously studied (Figure 7). Figure 10(h) shows some agglomerated particles on the surface of the material with similar morphology to the KC sample.

Figure 10(i), corresponding to the KEt5U sample, presents particles with a more uniform size than the KC and KEt5M samples. In this case, there is morphology in the form of stacked sheets without porosity with a preferential orientation, as observed in the identified area (Figure 10(j)), which is a different morphology when compared with the KC and KEt5M samples. In Figures 10(k) and 10(l), there are particles with the characteristics of the $\mathrm{KC}$ sample, i.e., agglomerates of compact hemispherical particles with radii of the order of $500 \mathrm{~nm}$ $(0.5 \mu \mathrm{m})$, which are also located on the surface.

In general, the results of the EDS microanalysis show the presence of the main elements of the structure of feather keratin $\mathrm{C}, \mathrm{O}, \mathrm{S}, \mathrm{N}$, and $\mathrm{Na}$ from the extraction process.

3.7. Particle Size. The Zetasizer nano ZSP equipment made an average of 3 measurements per sample to obtain the $Z$ average, which is shown in Figure 11.

The obtained particle size ( $Z$-average) is reported in Table 3. 


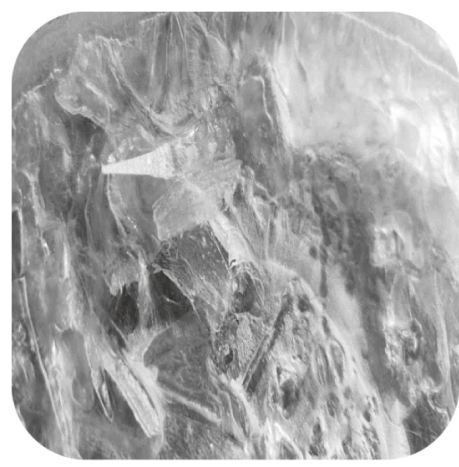

(a)

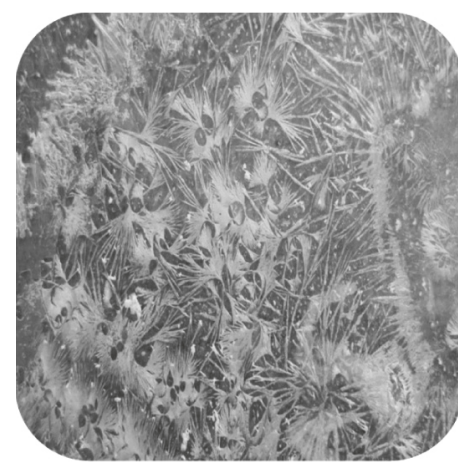

(b)

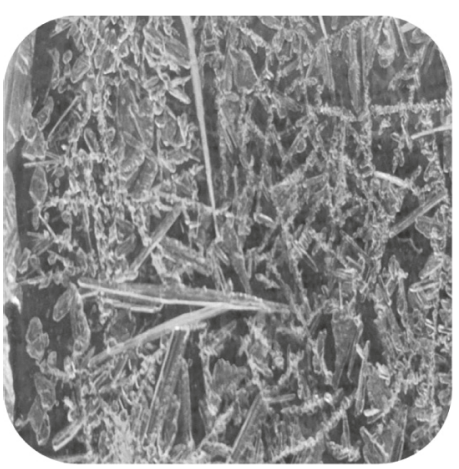

(c)

Figure 9: Optical microscopy 10x by the (a) conduction heating (KC), (b) microwave (KMO), and (c) ultrasound (KUS) samples.

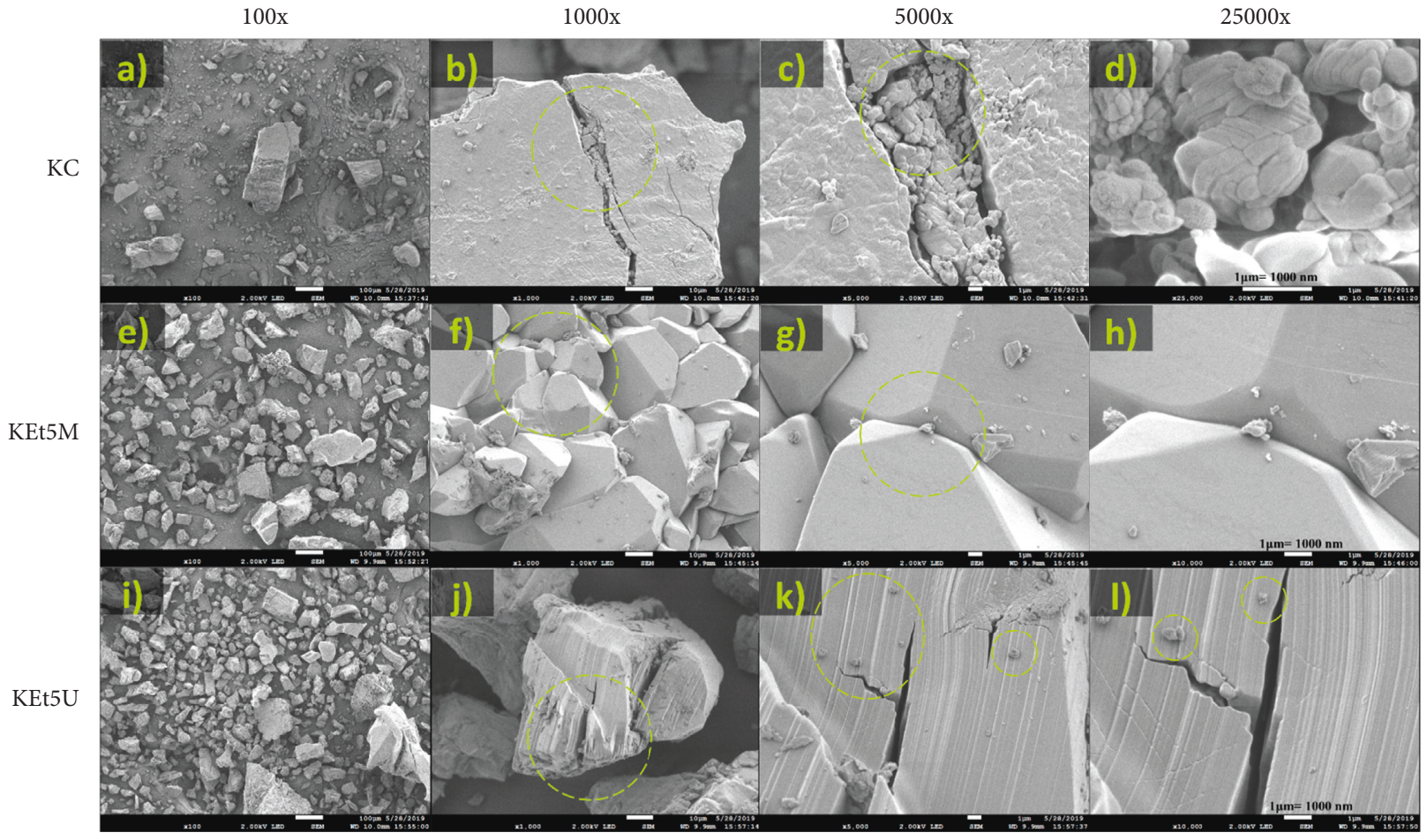

FIGURE 10: Scanning electron micrographs at different magnifications for the KC: (a) 100x, (b) 1000x, (c) 5000x, and (d) 25000x; KEt5M: (e) 100x, (f) 1000x, (g) 5000x, and (h) 25000x; KEt5U: (i) 100x, (j) 1000x, (k) 5000x, and (l) 25000x samples.

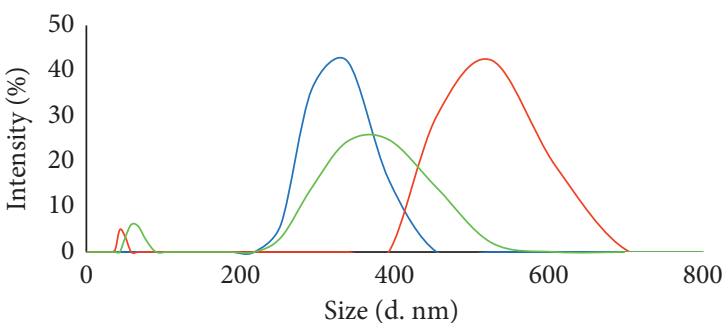

— KC: Measure 1

KC: Measure 2

- KC: Measure 3

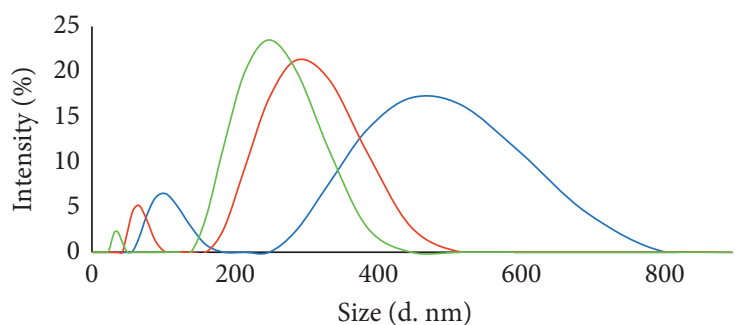

— KEt5U: Measure 1

_ KEt5U: Measure 2

_ KEt5U: Measure 3

(a)

(b)

Figure 11: Continued. 


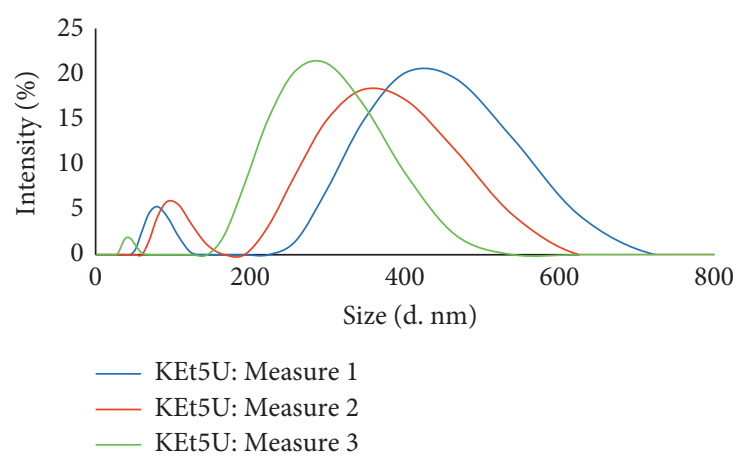

(c)

FIgUre 11: The particle size distribution of the KC (a), KEt5U (b), and KEt5M (c) samples.

TABLE 3: Particle sizes of the recrystallized samples.

\begin{tabular}{lc}
\hline Samples & $Z$-average $(\mathrm{nm})$ \\
\hline KC & $753-1428$ \\
KEt5U & $656-1100$ \\
KEt5M & $633-806$ \\
\hline
\end{tabular}

The particle size is smaller in the KEt5M sample recrystallized by microwaves when compared with the one recrystallized by ultrasound (KEt5U sample) and in both cases smaller by approximately $1000 \mathrm{~nm}$ with the KC sample (conduction heating). This indicates that the microwave and ultrasound methods make it possible to design materials which depend on the time and power of irradiation $[16,31]$.

\section{Conclusions}

The feather keratin is a fibrous biopolymer with low fat content (1.5\%).

The thermogravimetric analysis showed that the obtained material is resistant to temperatures of up to $800^{\circ} \mathrm{C}$.

The crystallinity depends on the irradiation time, the optimum being 5 minutes for microwaves and ultrasound, where the microwave-irradiated sample has a higher crystallinity.

The time and type of irradiation modify the crystallinity and the structure of feather keratin, predominating the beta structure when microwave and ultrasound irradiation are used; ultrasound irradiation promotes the growth in the direction (331) of the alpha structure.

The morphology depends on the method of irradiation used in the recrystallization stage. When optical microscopy was employed for the conduction heating method, a morphology of thin leaflets was found, whereas needles with ramifications and needles with an undefined orientation were obtained by microwaves and ultrasound, respectively. The details of these results were corroborated by SEM at higher magnifications with additional information: the thin leaflets are composed by compact monoliths, the needles with ramifications by faceted particles with prismatic tendency, and the needles with an undefined orientation by unidirectional laminar structures.
The texture of the materials is modified depending on the type of irradiation, finding compact solids with little porosity in all cases, materials with smaller particle size, greater surface area, and smaller pore diameter than the conduction heating method.

\section{Nomenclature}

KC: $\quad$ Keratin obtained by the conduction heating with water

KEt: $\quad$ Keratin obtained by the conduction heating with water-ethanol wash

KEt5M: Keratin obtained by the conduction heating with water-ethanol wash, 5 minutes microwave irradiation

KEt5U: Keratin obtained by the conduction heating with water-ethanol wash, 5 minutes ultrasound irradiation

Ket10M: Keratin obtained by the conduction heating with water-ethanol wash, 10 minutes microwave irradiation

KEt10U: Keratin obtained by the conduction heating with water-ethanol wash, 10 minutes ultrasound irradiation

KEt15M: Keratin obtained by the conduction heating with water-ethanol wash, 15 minutes microwave irradiation

KEt15U: Keratin obtained by the conduction heating with water-ethanol wash, 15 minutes ultrasound irradiation

BET: $\quad$ Brunauer, Emmet, and Teller

BJH: Barrett, Joyner, and Halenda.

\section{Data Availability}

The data supporting the conclusions in this work are included in this manuscript. Other datasets generated and analyzed during the current work are available from the corresponding author on reasonable request.

\section{Conflicts of Interest}

The authors declare no conflicts of interest. 


\section{Acknowledgments}

The authors would like to thank Instituto Politécnico Nacional (IPN) (SIP20196290, SIP 20196381, and SIP 20181685 projects) and Laboratorio de Nanomateriales Sustentables IPN-ESIQIE for their support. I.S.R.C. thanks CONACYT for the scholarship support (564818).

\section{References}

[1] J. Schweizer, P. E. Bowden, P. A. Coulombe et al., "New consensus nomenclature for mammalian keratins," The Journal of Cell Biology, vol. 174, no. 2, pp. 169-174, 2006.

[2] P. A. Coulombe and M. B. Omary, "Hard" and "soft" principles defining the structure, function and regulation of keratin intermediate filaments," Current Opinion in Cell Biology, vol. 14, no. 1, pp. 110-122, 2002.

[3] B. Wang, W. Yang, J. McKittrick, and M. A. Meyers, "Keratin: structure, mechanical properties, occurrence in biological organisms, and efforts at bioinspiration," Progress in Materials Science, vol. 76, pp. 229-318, 2016.

[4] No Title. (n.d.), http://www.femexer.org/10943/sindrome-deresistencia-a-la-insulina-tipo-b/.

[5] A. Shavandi, T. H. Silva, A. A. Bekhit, and A. E.-D. A. Bekhit, "Keratin: dissolution, extraction and biomedical application," Biomaterials Science, vol. 5, no. 9, pp. 1699-1735, 2017.

[6] J. McKittrick, P.-Y. Chen, S. G. Bodde, W. Yang, E. E. Novitskaya, and M. A. Meyers, "The structure, functions, and mechanical properties of keratin," Jom, vol. 64, no. 4 , pp. 449-468, 2012.

[7] T. Korniłłowicz-Kowalska and J. Bohacz, "Biodegradation of keratin waste: theory and practical aspects," Waste Management, vol. 31, no. 8, pp. 1689-1701, 2011.

[8] A. Nadda and S. Sharma, Keratin as a Protein Biopolymer: Extraction from Waste Biomass and Applications, Springer, Berlin, Germany, 2019.

[9] P. Novák and V. Havlíček, "4-protein extraction and precipitation," in Proteomic Profiling and Analytical Chemistry, pp. 51-62, Elsevier, Boston, MA, USA, 2016.

[10] J. Wang, S. Hao, T. Luo et al., "Feather keratin hydrogel for wound repair: preparation, healing effect and biocompatibility evaluation," Colloids and Surfaces B: Biointerfaces, vol. 149, pp. 341-350, 2017.

[11] S. Al-Asheh, F. Banat, and D. Al-Rousan, "Beneficial reuse of chicken feathers in removal of heavy metals from wastewater," Journal of Cleaner Production, vol. 11, no. 3, pp. 321-326, 2003.

[12] T. Posati, D. Giuri, M. Nocchetti et al., "Keratin-hydrotalcites hybrid films for drug delivery applications," European Polymer Journal, vol. 105, pp. 177-185, 2018.

[13] S. Cheng, K.-T. Lau, T. Liu, Y. Zhao, P.-M. Lam, and Y. Yin, "Mechanical and thermal properties of chicken feather fiber/ PLA green composites," Composites Part B: Engineering, vol. 40, no. 7, pp. 650-654, 2009.

[14] K. Yamauchi, A. Yamauchi, T. Kusunoki, A. Kohda, and Y. Konishi, "Preparation of stable aqueous solution of keratins, and physiochemical and biodegradational properties of films," Journal of Biomedical Materials Research, vol. 31, no. 4, pp. 439-444, 1996.

[15] J. H Buchanan, "A cystine-rich protein fraction from oxidized $\alpha$-keratin," Biochemical Journal, vol. 167, no. 2, pp. 489-491, 1977.

[16] M. Zoccola, A. Aluigi, A. Patrucco et al., "Microwave-assisted chemical-free hydrolysis of wool keratin," Textile Research Journal, vol. 82, no. 19, pp. 2006-2018, 2012.
[17] Y. Tsuda and Y. Nomura, "Properties of alkaline-hydrolyzed waterfowl feather keratin," Animal Science Journal, vol. 85, no. 2, pp. 180-185, 2014.

[18] K. Katoh, M. Shibayama, T. Tanabe, and K. Yamauchi, "Preparation and physicochemical properties of compressionmolded keratin films," Biomaterials, vol. 25, no. 12, pp. 2265-2272, 2004.

[19] H. Xie, S. Li, and S. Zhang, "Ionic liquids as novel solvents for the dissolution and blending of wool keratin fibers," Green Chemistry, vol. 7, no. 8, pp. 606-608, 2005.

[20] W. Si, C. Ding, and S. Ding, "Synthesis and characterization of YAG nanoparticles by ultrasound-assisted and ultrasoundmicrowave-assisted alkoxide hydrolysis precipitation methods," Journal of Nanomaterials, vol. 2014, Article ID 408910, 8 pages, 2014.

[21] Y. Zarazua-Aguilar, S. P. Paredes-Carrera, J. C. SánchezOchoa, J. R. Avendãno-Gómez, and S. O. Flores-Valle, "Influencia de la irradiacíon microondas/ultrasonido en la síntesis sol-gel de nano partículas de díoxido de titanio para su aplicacíon en fotocátalisis," Revista Mexicana de Ingeniería Química, vol. 16, no. 3, pp. 899-909, 2017.

[22] A. Şencan and M. Kiliç, "Investigation of the changes in surface area and FT-IR spectra of activated carbons obtained from hazelnut shells by physicochemical treatment methods," Journal of Chemistry, vol. 2015, Article ID 651651, 8 pages, 2015.

[23] D. O. S. Ramirez, R. A. Carletto, C. Tonetti, F. T. Giachet, A. Varesano, and C. Vineis, "Wool keratin film plasticized by citric acid for food packaging," Food Packaging and Shelf Life, vol. 12, pp. 100-106, 2017.

[24] E. Rangel Robles, Extracción de la queratina del cabello por medio de una hidrolisis ácida, Instituto Politécnico Nacional, Mexico City, Mexico, 2013.

[25] A. Aluigi, M. Zoccola, C. Vineis, C. Tonin, F. Ferrero, and M. Canetti, "Study on the structure and properties of wool keratin regenerated from formic acid," International Journal of Biological Macromolecules, vol. 41, no. 3, pp. 266-273, 2007.

[26] E. Wojciechowska, A. Włochowicz, and A. WesełuchaBirczyńska, "Application of fourier-transform infrared and raman spectroscopy to study degradation of the wool fiber keratin," Journal of Molecular Structure, vol. 511-512, pp. 307-318, 1999.

[27] P. Erra, N. Gómez, L. M. Dolcet, M. R. Juliá, D. M. Lewis, and J. H. Willoughby, "FTIR analysis to study chemical changes in wool following a sulfitolysis treatment," Textile Research Journal, vol. 67, no. 6, pp. 397-401, 1997.

[28] W. G. Murrell, "The biochemistry of the bacterial endospore," in Advances in Microbial Physiology, A. H. Rose and J. F. Wilkinson, Eds., vol. 1, pp. 133-251, Academic Press, Cambridge, MA, USA, 1967.

[29] S. P. Paredes, M. A. Valenzuela, G. Fetter, and S. O. Flores, " $\mathrm{TiO}_{2} / \mathrm{MgAl}$ layered double hydroxides mechanical mixtures as efficient photocatalysts in phenol degradation," Journal of Physics and Chemistry of Solids, vol. 72, no. 8, pp. 914-919, 2011.

[30] R. M. Silverstein, F. X. Webster, D. J. Kiemle, and D. L. Bryce, Spectrometric Identification of Organic Compounds, John Wiley \& Sons, Hoboken, NJ, USA, 2014.

[31] I. J. Joye and D. J. McClements, "Production of nanoparticles by anti-solvent precipitation for use in food systems," Trends in Food Science \& Technology, vol. 34, no. 2, pp. 109-123, 2013. 


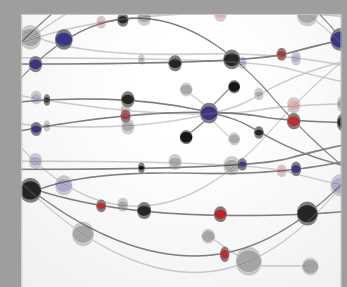

The Scientific World Journal
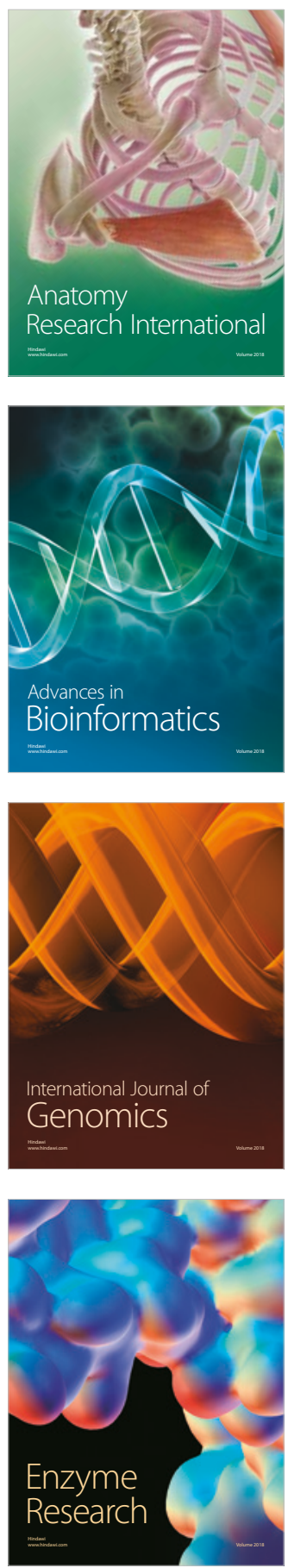
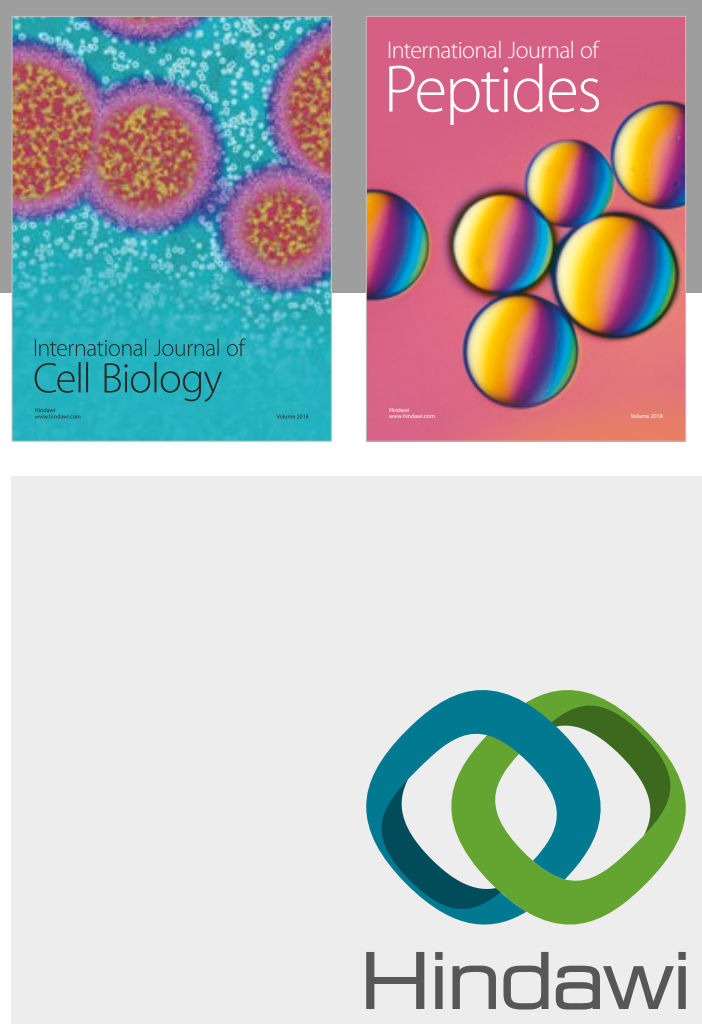

Submit your manuscripts at

www.hindawi.com
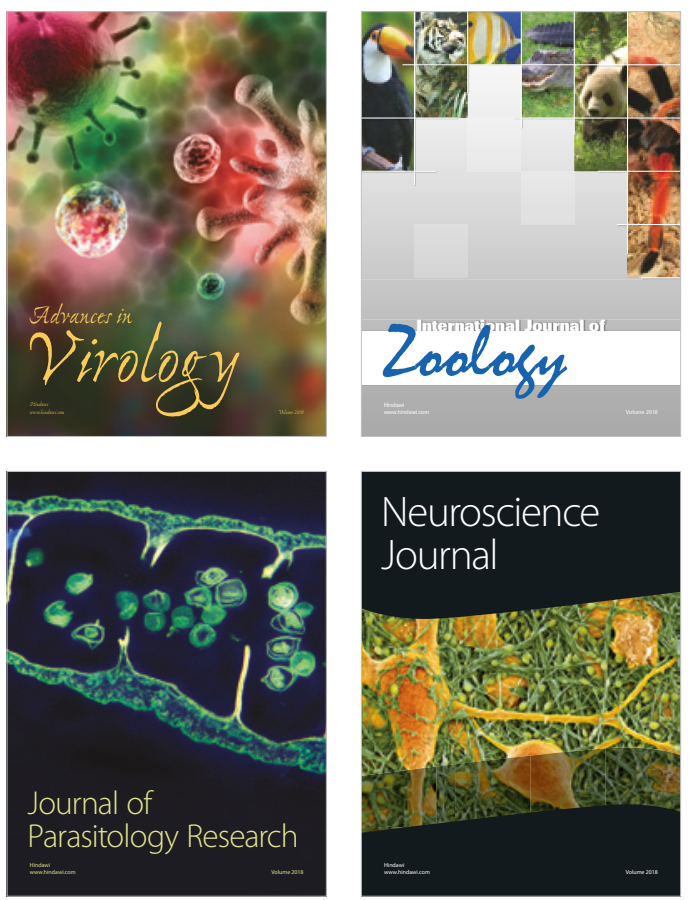
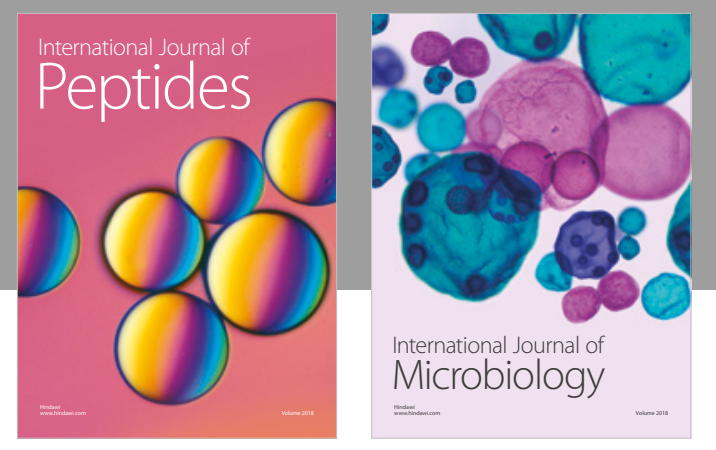

nternational Journal of Microbiology
Journal of
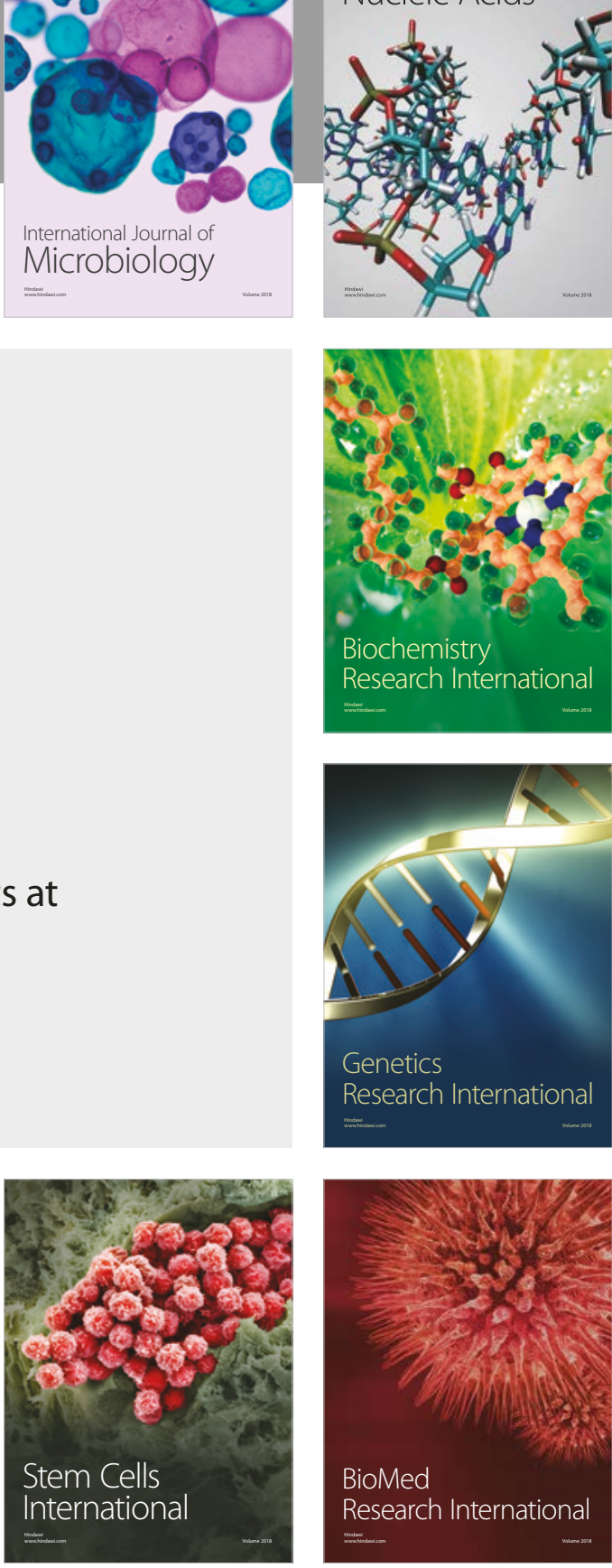
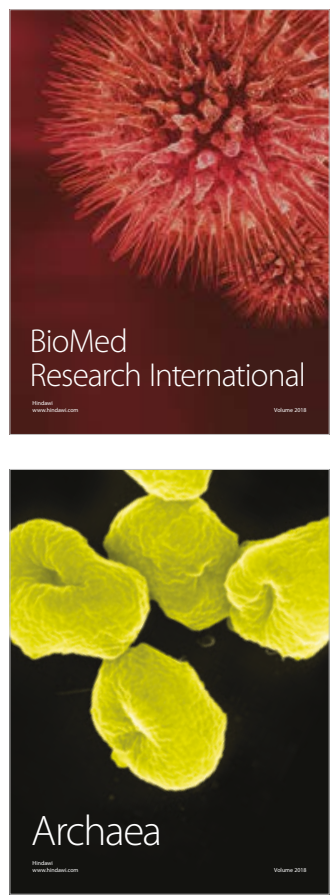